\title{
The State and Industrial Research Associations. ${ }^{1}$
}

\section{By J. W. Williamson, Secretary, British Scientific Instrument Research Association.}

I. WHEN in I9I6́ the Government of the day set aside a sum of $\mathrm{I}, 000,000 l$. to be expended in promoting scientific and industrial research, the Committee of the Privy Council for Scientific and Industrial Research, on the advice of its Advisory Council, decided that the sum should be expended in grants in aid to industrial research associations to be established for the purpose of conducting research on a co-operative basis. There were those who suggested that the best way of ensuring an extensive application of scientific research to industrial problems was to subsidise existing research agencies, whether in the universities and technical colleges or elsewhere; or to establish and endow in the country one or more research institutes after the type, say, of the Mellon Institute of Industrial Research in the U.S.A.

I think it will be granted by most, if not by all, of the members of this Conference that the decision actually taken was the wisest course ; for one thing, because it was the only scheme which promised to secure the continuous co-operation in research of the industries presumed to be in need of research, and to get science domiciled in those industries. The experience of the last eleven years goes to show that it is only through some such agency as the industrial research associations that in many industries, though perhaps not in all; a real fusion of scientific knowledge and industrial experience andwhat is equally important-a working co-operation of the scientific workers and the manufacturers can be effected.

2. There was, however, one principle laid down by the Committee of the Privy Council for the promotion of Scientific and Industrial Research, the body responsible for the administration of the million fund, which needs special examination to-day. It was stated, almost as though it were axiomatic, that the Government grant to the research associations, as and when they were established in accordance with the scheme, must be limited to a definite period, after which the associations must be independent of State financial aid. The period originally chosen was a period of five years, afterwards extended, for many research associations, to ten years.

If, as I am inclined to think, the limitation of the Government grant to a definite period of time was a policy deliberately adopted as being based, or assumed to be based, on certain accepted principles of political economy or in accord with recognised limits of State action, then I submit that experience has shown this policy to be of doubtful wisdom.

3. It is important at the outset to be quite clear as to the function of Government in this particular field of industrial research. It all depends whether the persuasion of the industries as to the value of research is put in the first place and the carrying out of industrial research in the second; or whether the extension of industrial research is put in the first place and the persuasion of the industries as to its value in the second. The first view leads directly to the principle of grant for a limited period; the second view implies some continuity of grant.

It is noteworthy that in regard to what is called 'pure' scientific research the Government adopts the second view. The grants to universities and kindred bodies, largely intended for 'pure' scientific research, are regarded as permanent in character.

"A paper entitled "Should the Government Gront to Research Associations be limited to a Period of Years?" read at a Conference of Research Associations on July 22.
There is no suggestion that they should be limited to a period sufficient to persuade any persons or bodies of the value of 'pure' scientific research. It is the same with regard to education grants generally. No responsible person to-day suggests that Government grants for education should be continued only so long as may reasonably be necessary to persuade parents generally of the value of education. In these instances the Government regards it as a primary and paramount duty to ensure that, in one, 'pure' scientific research is carried out, and, in the other, that education is given. The appreciation by the sections of the community concerned of the value of pure research or of education is a secondary, though an important, consideration. It is worth remark here that much of the work of the research associations belongs to the categories of pure research and education.

Moreover, in certain fields of industrial research, as, for example, fuel, food, and forest products, the Department made no question that it was properly the duty of the State to finance wholly such " national researches. There was not the slightest squeamishness about expending the taxpayers' money on such researches; and rightly so, for the taxpayer, quá citizen, is an ultimate beneficiary of the results of such research.

4. In that region of industrial research assigned to the research associations, however, the emphasis was the other way. The policy was designed apparently with the main object of convincing manufacturers of the value of scientific research by subsidising the research associations for such a period as could reasonably be estimated to be needed to bring conviction. In so far as it succeeded in that period in convincing the industries that it was worth their while to bear the whole burden of research the scheme succeeded; in so far as it failed to do this the scheme itself failed.

It was probably felt that to commit the State to a permanent subvention-or at least a subvention not limited in time- of industrial research, in those particular fields of industry covered by the research associations, would come too near to subsidising those manufacturers who were members of the associations at the expense of the rest of the community. I do not seek to impugn the validity of such a principle or to weaken the force of such a healthy feeling, especially in these days, but I think that in this case certain factors have been overlooked, or at least have not been taken fully into account.

5. In the first place, it has to be recognised that it is impossible by scientific research to benefit the particular manufacturers who are members of the research association related to a given industry without conferring benefits, though to a less degree, on other manufacturers in the same industry who are not members of the association, and without benefiting also the community as a whole by the increased efficiency of the industry concerned, directly attributable to the research work done. I am not here hinting at any leakage of confidential information, though it is generally agreed that the period during which information of value can be kept confidential is limited. I am referring to those general processes of industrial diffusion which are always in operation. New ideas have a way of getting into the air. It is a well-known experience that increased efficiency on the part of some firms in an industry has stimulating effects on, and tends to raise the efficiency of, the rest of the firms in 
that industry. To carry the matter further, the raising of the standard of efficiency in one industry has inevitably beneficial reactions on many other industries. These consequences are not limited in time but are continuous, and, I submit, there is ample justification, on purely business grounds, for asking the taxpayer to contribute continuously, so that this fertilising stream of research may continue to irrigate the particular fields of industry concerned, to the taxpayers' ultimate benefit.

6. In the second place, it has to be remembered that in many cases the contribution of the manufacturer to the research association of which he is a member is only a part of the contribution which he makes to scientific and industrial research. Many of the manufacturing firms have research departments of their own. In some cases the sums annually expended to maintain and develop these private research departments are much greater, even by many times, than the annual subscription to the research association. Moreover, and this is especially important, the work of the research associations has tended, and will tend more, to stimulate further expenditure on these private research departments. I may mention, for example, that one firm, a member of the research association with which I am connected, testified, after only two years' experience as a member of the association, that the work of the association had given them increased confidence in their own research work so that they had doubled their annual expenditure under that head.

No doubt other research associations could bring forward similar testimony. This consideration may not apply as yet, in the same degree or to a like extent, to all the industries covered by the research associations; it is perhaps only well marked at present in those industries which have always had intimate relations with science. But the important point to be borne in mind is that, if the research association scheme is to develop all its capacities, such an experience must ultimately be a common experience in all the industries that support cooperative research. If and as the research associations become stable and vigorous institutions in our industrial organisation, the manufacturers will be led to increase the quota of their contributions to research, notwithstanding that, so far as the actual subscriptions to the research associations are concerned, they might continue to be on a pound-forpound basis.

7. There is, therefore, no need for those who are responsible for directing the national policy as to research associations to feel that, if the Government continues indefinitely to support the research associations on, say, the pound-for-pound basis, they are subsidising one section of the community without ensuring collateral and proportionate benefits to the community as a whole. Nor need they fear that the continuous grant of the Government's annual pound will result in the manufacturers restricting their expenditure on research to an equal amount. The grant in aid would be dynamic. 'For every pound expended by the Government to subsidise the research associations on, nominally, a pound-for-pound basis, there would be a steadily increasing expenditure by the industries on research, both absolutely and relatively to the grant in aid.

It is by that method and along those lines that the industries can be best persuaded, ambulando, to increase continuously their expenditure on research, and thus to realise in substance the whole object of the research associations scheme. I submit, from the considerations already advanced and from others which will follow immediately, that to rely on the continuity of grant to bring about naturally and, as it were, automatically increased expenditure by industries on scientific research, is likely to be more effective in the long run than the method now adopted of giving grants for a limited period on a descending scale, so as at the end of the period to throw on the industries concerned the whole financial burden of supporting the research associations.

8. There is another aspect of the question which must make us doubt whether the proposal to cease grants to the research associations after a limited period is wise in the national interest. At present, and so long as Government makes grants in aid to research associations, Government has full knowledge of all that the research associations are doing; it has wide powers of regulation and control ; it has numerous and recurring opportunities of co-ordination; it has powers to act, in the national interest, so that important results of research may not be confined too exclusively to any one industry where they are of actual or potential value to other industries; and, generally, through the Department of Scientific and Industrial Research, it acts as the focus and centre of the work of all the research associations.

The Department of Scientific and Industrial Research has shown, by sympathy and insight, how it is possible to reconcile the exercise of these powers of control, regulation, and co-ordination with the freedom and elasticity necessary to the research associations individually if their work is to be of productive value. If and when Government grants to research associations cease, these functions of Government must cease too, or at least be so curtailed as to lose their virtue, the consequences must be that the direct advantages now accruing to the Government services by the present liaison between Government and the research associations will be lost; the advantages to the nation as a whole, resulting from the power of the Government, through the Department of Scientific and Industrial Research, to secure correlation and co-ordination in important areas of industrial research, will disappear; and even the researches into 'national' problems, such as fuel, food, and forest products, must lose something when contacts between the Department of Scientific and Industrial Research and the research associations are broken. The very structure of our industrial system may be profoundly modified by the work of the research associations and the Government, by cutting itself adrift from these developments, be ignorant of their character and scope and be powerless to influence them.

It is worth notice here that the late Prof. Alfred Marshall, the distinguished economist, raised a cognate argument in his "Industry and Trade," first published in I919. Referring to the research associations, and after pointing out that they are " wholly constructive," he says :

"But the experience of the ages shows that associations set up for constructive purposes are in danger of being turned to destructive ends: and therefore it may perhaps be to the public interest that some limited contribution should be made from public funds to the support of such associations, partly in order to facilitate the intervention of public authority in case an association should develop anti-social tendencies."

I have not time to examine the interesting implications of this passage, and I must be content to let the quotation speak for itself.

9. Another serious consequence of a divorce of the Government from the research associations, such as must necessarily follow from a discontinuance. 
of grants in aid, would be the weakening of the principle of co-operation. The research associations scheme is a scheme based on the conception that in scientific research, no less than in trade, there is a vast area in which the work needed to be done can be done effectively only by co-operation. One of the strongest arguments for such co-operative research is that, by its means, researches of vital importance to the respective industries can be undertaken, though they may be of a nature and extent which would make it impossible for any individual firm to undertake them. It is true that, theoretically, the research associations would still be free to undertake such researches even if Government grants ceased and relations with the Department of Scientific and Industrial Research were severed. In practice, however, there can be little doubt that the loss of the Government grant and the severance of relations with the Department of Scientific and Industrial Research would tend to discourage the research associations from undertaking these larger researches into problems not, at first sight, promising immediate benefits to the industry. When the industry has to find all the money for co-operative research, there will naturally be a tendency on the part of the industry to concentrate more and more on research work deemed likely to bring immediate or early benefits to the industry, and to postpone to a never-coming to-morrow those wider investigations which might not seem to promise results of immediate industrial value. It is because the continued association of the Government with the research associations helps the research associations to develop to the fullest extent all the capacities of co-operative research-because, shortly, the co-operative research is not fully co-operative without the co-operation of the Department of Scientific and Industrial Research - that the policy of putting a definite term to grants in aid is, in the national interest, mistaken.

Io. The Advisory Council in its report to the Committee of the Privy Council for the year 1916-17 (Cd. 87I 8 , p. I6) stated that there seemed to be room in the industrial world for three methods of financing research. "There is research which the individual firm finds it remunerative to undertake at its own expense. Secondly, there is research which is financed on a co-operative basis; and lastly, there is research which must be financed by the State if it is to be done at all." I submit that, in the national interest, the phrase "financed on a co-operative basis " should be interpreted as including the continuous financial co-operation of the State.

I do not pretend in this paper to have done more than to have touched lightly a few of the points that must arise in a discussion of this important matter. I hope, however, that I have said enough to show that the principle of limiting State aid to research associations to a definite and comparatively short term of years is neither axiomatic nor sacrosanct, but, judged from the national interest, and even by that criterion alone, of dubious value.

\section{Sir Charles Parsons and the Steam Turbine.}

$T^{H}$

HE presentation of the Kelvin Medal to Sir Charles Parsons, and the delivery of the James Forrest Lecture on "Radio Communications" by Senator Marconi, took place on October 26 at the Institution of Civil Engineers. The assembly was the largest ever seen at the Institution ; and among those present was the Italian Ambassador. In presenting the medal on behalf of the Kelvin Medal Award Committee, Sir William Ellis, the president of the Institution, referred to the work of Sir Charles Parsons in the fields of scientific inquiry and the applications of thermodynamics, remarking that the medal commemorated the achievements of Lord Kelvin in those branches of science which are especially applicable to engineering. Reference was made to the scientific environment in which Sir Charles Parsons was brought up and to the work of his father, the Earl of Rosse, who in 1845 completed the famous reflecting telescope at Birr Castle, and later Sir William Ellis sketched the progress of the steam turbine with which the name of Sir Charles Parsons is so closely associated.

The acknowledgment of the gift of the medal by Sir Charles Parsons was followed by some reminiscences of great interest. $\mathrm{He}$ touched upon his boyish attempts to construct models of such materials as were available - a far better thing for a boy than playing with mechanical toys. One of his early inventions was a sounding machine with a glass tube closed at the end, somewhat similar to that of Lord Kelvin, but, said Sir Charles humorously, "I believe Kelvin's invention was made independently." Sir Charles also reminded his hearers of his experiments in making diamonds, which, however, when tested, proved not to be diamonds at all. He still thought something might be done in that direction. When engaged with the steam turbine, the financial and commercial difficulties were greater than the scientific and mechanical, and he recalled with pleasure the favourable opinion of the turbine expressed by Lord Kelvin on more than one occasion. It was a notable day in the history of the turbine when the turboalternator set supplied to Cambridge in $\mathrm{I} 892$ showed an economy superior to the reciprocating engines of that time.

Sir Charles Parsons was born on June 15, I854, being the fourth son of the third Earl of Rosse. A glimpse of his early surroundings can be obtained from the "Reminiscences" of Sir Robert Ball, who in 1865 became tutor to Sir Charles and his two brothers. After being privately educated he entered St. John's College, Cambridge, and graduated in I 876, being eleventh wrangler. Four years were then spent at the famous Elswick Works, where he came under the influence of Lord Armstrong, and in I 883 he became junior partner in the firm of Clarke; Chapman, Parsons and Co., of Gateshead, where he began his life's work on the steam turbine.

Many patents for rotary engines were taken out during the nineteenth century, but modern turbine work begins with those of 1884 . First came the patent of the Swedish engineer, Gustav de Laval, for an impulso turbine, and this was followed by those of young Sir Charles Parsons. Of the patents of April 23, I 884, No. 6734 was for "improvements in electric generation and in working them by fluid pressure," and No. 6735 was for "improvements in rotary motors actuated by elastic fluid pressure, and applicable also as pumps."

The pioneer Parsons turbine constructed was a double-ended parallel-flow machine, running at 18 , ooo revolutions per minute, driving an armature only $2 \frac{5}{8}$ inches in diameter. This little machine was used in the Inventions Exhibition of $\mathbf{1} 885$, and is now at the Science Museum, South Kensington. By I889, 300 turbo-generators had been constructed, the largest being 75 kilowatts. Soon after this the firm of C. A. Parsons and Co. was founded, followed a few 